\title{
Activated ceramic compositions with the addition of serpentinite
}

\author{
Irina Enzhievskaya ${ }^{1}$, Nina Vasilovskaya ${ }^{1}$, and Vadim Savchenko ${ }^{1, *}$ \\ ${ }^{1}$ Siberian Federal University, 660041, Svobodny ave., 79, Krasnoyarsk, Russia
}

\begin{abstract}
The article describes the loam of the Kubekovsky deposit of the Krasnoyarsk Territory, which is widely used in the production of ceramic bricks in factories that produce wall materials. In the studies described in the article, mechanoactivation and modification were used to improve its technological and physico-mechanical characteristics. Mechanoactivation was carried out in a hydrodynamic dispersant. As the additive-modifier used waste stoneplant serpentinites of the Perevalnoye deposit. The effect of the additive-modifier on the properties of ceramic compositions is shown. It is shown that a small amount of serpentinite - up to three percent - significantly increases the compressive strength of fired ceramic samples. If the composition has an additive of more than three percent, a decrease in strength characteristics is observed, this is related, probably due to the fact that most of the magnesium oxide remains unreacted. White inclusions are observed visually in the structure of calcined samples throughout the volume. The combined effect of mechanoactivation and modification is shown, which makes it possible to improve the technological and physicomechanical characteristics of the ceramic shard. The results of electron microscopy are presented, suggesting that the microstructure of a ceramic shard activated with the addition of serpentinite contains more mullite-rich mixed crystals, as well as devitrified areas. Inclusions of magnesium oxide are not observed. Magnesium oxide in the ceramic composition serves as a primer capable of making the melt more liquid, accelerating its devitrification.
\end{abstract}

According to the concept of long-term development of the Russian Federation for the period up to 2020 (outlined in the Order of the Government of the Russian Federation No. 1662-r of November 17, 2008), it is necessary to gradually reduce the levels of environmental impact of all anthropogenic sources. For many decades, poles of ecological disadvantage have been formed in Russia, especially in industrial regions, including Siberia and the Krasnoyarsk Territory, which negatively affects people's quality of life, their health, and life expectancy.

The dynamics of the main environmental indicators of Russia's development shows an increase in the negative impact on the environment (total waste generation volumes against the background of a decline in the level of their processing). Therefore, the use of waste

\footnotetext{
* Corresponding author: vadim.savchenko.1993@ mail.ru
} 
and related products in the production of building materials and the greening of production (a gradual reduction in the environmental impact of all anthropogenic sources) is an important contemporary task.

Ceramic industry around the world (including in Russia and especially in the Siberian region) is a dynamically developing industry. Up to $70 \%$ of the total urban construction is made of bricks and ceramic stones.

However, very often clay raw materials are of poor quality. The possibilities for improving the properties of clay raw materials are very limited, as the technology for obtaining ceramics is high-temperature processing. Since modern construction is on the way to improve the efficiency of wall products by creating a significant number of technological cavities with thin ceramic partitions, very high quality raw materials are required, when firing, the probability of deformation of thin partitions and the decrease in the physical and mechanical characteristics of the material are much higher.

At present, the results of scientific developments in the part of using industrial waste to improve the quality of building materials are poorly introduced in Russia. A number of works are devoted to the expansion of the raw material base for the production of wall ceramics and possible ways of modifying the ceramic masses $[1,2,4,5]$. In the papers $[1$, 2], the chemical and mineralogical composition of the initial clay raw material, the possibility of using surfactant additives, their plasticizing and structuring effect on the molding and drying properties.

The issues of complex modification of clay raw materials and the use of technogenic raw materials for this purpose, which provide an intensifying effect on the processes of phase formation and structure formation in a ceramic shard, are devoted to a number of scientific developments [3-5]. The experience of using magnesite waste in the technology of manufacturing high-strength ceramics [6], man-made serpentinite raw materials [7], the use of industrial waste for the production of ceramic building materials [8, 9].

The increasing quality of ceramic materials with the use of associated raw materials and industrial wastes was carried out by such foreign sholars as R. R. Menezes, A. A. Francis, G. A. Khater, S. K. Amin, F. J. P. Sousa [11-16].

A significant amount of work is devoted to the improvement of the quality of clay raw materials by mechanoactivation. In Russia, one of the first who in this direction worked was F. M. Flavitsky, who observed the progress of solid-phase reactions in the mechanical processing of powders [17]. V. B. Zaalishvili considered the influence of mechanical influence on the physical and chemical characteristics of rocks [18]. The change in the fractional composition of oil under hydroimpulse cavitation treatment was also studied [19]. D. S. Tsyplakov, A. V. Kornilov, T. Z. Lygina and E. N. Permyakov investigated the process of mechanoactivation of clay raw materials on various equipment [20]. The scientists found that as a result of mechanoactivation, the sinterability of the activated raw material improves, and the strength characteristics of ceramics on its basis increase.

A review of foreign experience shows that mechanoactivation is increasingly used in improving the quality of building materials [21, 22].

In connection with the foregoing, the current task of building materials is to reduce the level of environmental impact by using industrial waste in the manufacture of ceramic products in order to improve the physical and mechanical properties of clay raw materials.

The purpose of this work is to increase the technological and physicomechanical properties of clay raw materials through its mechanoactivation and modification by industrial waste in order to produce wall ceramic products with increased efficiency.

In the paper, low-melting loams of the Kubekovskoye deposit, located on the West Siberian plate of the Krasnoyarsk Territory, were used. The reserves of the field are very significant, but the raw materials need to be adjusted with refractory clays to produce high- 
quality products. The chemical composition of the loam of the Kubekovskoye deposit is presented in Table 1.

In the production of ceramic bricks, the Kubekovskie loam is optimized with the help of an additive expensive refractory clay of the Cantata deposit in an amount of up to $25 \%$. If a solid brick with the required physical and mechanical properties can be obtained using this technological method, then for the production of effective ceramic materials, stones with thin partitions, high quality cannot be obtained because of low physic and mechanical parameters of loam and additional technological measures are required.

To increase the technological characteristics of the loam, we used the mechanoactivation in the hydrodynamic dispersant and modification of the waste rocking serpentinites of the Perevalnoye deposit (a pulp). The chemical composition of the investigated additive serpentinite is given in Table 1.

Serpentinite was introduced into a clayey charge to improve the physical and mechanical characteristics of the shard and utilization of stone-wastes in the amount of 1,3 , $6 \%$ of the Kubekovsky loam's mass.

Table 1. Chemical composition of loam with serpentinite from the Kubekovsky deposit.

\begin{tabular}{|c|c|c|c|c|c|c|c|c|c|}
\hline \multicolumn{1}{|c|}{ Composition, \% } & \multicolumn{9}{|c|}{ Content of oxides, mass \% } \\
\hline Cub. & Serpen. & $\mathrm{SiO}_{2}$ & $\mathrm{Al}_{2} \mathrm{O}_{3}$ & $\begin{array}{c}\mathrm{Fe}_{2} \mathrm{O}_{3}+ \\
\mathrm{FeO}\end{array}$ & $\mathrm{CaO}$ & $\mathrm{MgO}$ & $\mathrm{Na}_{2} \mathrm{O}$ & $\mathrm{K}_{2} \mathrm{O}$ & ППп \\
\hline 100 & 0 & 58,96 & 14,92 & 5,32 & 6,95 & 1,83 & 1,68 & 1,44 & 8,90 \\
\hline 0 & 100 & 40 & 1,99 & 7,34 & 0,49 & 38,1 & - & - & 11,6 \\
\hline 99 & 1 & 58,77 & 14,8 & 5,34 & 6,87 & 2,2 & 1,67 & 1,42 & 8,93 \\
\hline 97 & 3 & 58,4 & 14,54 & 5,38 & 6,76 & 2,92 & 1,62 & 1,38 & 8,98 \\
\hline 94 & 6 & 57,82 & 14,14 & 5,44 & 6,56 & 4,01 & 1,58 & 1,35 & 9,06 \\
\hline
\end{tabular}

An analysis of these test results showed that the addition of a serpentinite additive to the ceramic composition changes its chemical composition. There is a decrease in the $\mathrm{Al}_{2} \mathrm{O}_{3}$ aluminum oxide content from 14.92 to $13.75 \%$ and a slight increase in the amount of iron oxides $\mathrm{Fe}_{2} \mathrm{O}_{3}+\mathrm{FeO}$ from 5.35 to $5.5 \%$, which implies a reduction in the firing temperature of the composition, especially in view of the absence of the additive of refractory clay.

The addition of serpentinite as an additive to the ceramic composition leads to an increase in the magnesium oxide content of $\mathrm{MgO}$ from 1.83 to $5.1 \%$, which in a small amount, as a rule, leads to an increase in the strength characteristics of the ceramic shard.

For the production of ceramic compositions, a plastic molding method was used. The prepared samples of ceramic compositions with a different amount of serpentinite additive were fired in a muffle furnace according to the $500^{\circ} \mathrm{C}-700^{\circ} \mathrm{C}-950^{\circ} \mathrm{C}$ regime. Burned samples were used to determine fire and air shrinkage, physical-mechanical and operational properties, such as strength and density. The results of testing of ceramic compositions with the addition of serpentinite are given in Table 2 .

As can be seen from the test results, the addition of serpentinite in an amount of up to $3 \%$ inclusive leads to a significant increase in the strength of calcined ceramic compositions - from $7 \mathrm{MPa}$ to 10-13 MPa, and an increase in the flexural strength from 4.6 to $6 \mathrm{MPa}$. The increase in strength is probably due to the fact that the fine-dispersed silica and magnesium oxide released during the thermal decomposition of serpentine are chemically active and can interact with the components of the charge with a strengthening effect. It is established that a ceramic shard based on compositions with the addition of serpentinite in excess of $3 \%$ has reduced strength characteristics. It can be assumed that most of the magnesium oxide remains unreacted, as evidenced by white inclusions throughout the sample volume (Figure 1.a).

To further improve the physicomechanical characteristics, the ceramic compositions studied undergo mechanoactivation in a vortex cavitator, the principle of which is based on 
the hydrodynamic effect on the material at high speeds from 1 to $10,000 \mathrm{rpm}$. The test results of the activated compositions are given in Table 2.

Table 2. Physical and mechanical properties of ceramic compositions after firing.

\begin{tabular}{|c|c|c|c|c|c|c|}
\hline \multirow{2}{*}{$\begin{array}{c}\text { No. } \\
\begin{array}{c}\text { Compos } \\
\text { itions }\end{array}\end{array}$} & $\begin{array}{c}\text { Kubekovsky / } \\
\text { Serpentinite }\end{array}$ & $\begin{array}{c}\text { Proces. the } \\
\text { compos. in } \\
\text { the cavitat., } \\
\text { min. }\end{array}$ & $\begin{array}{c}\text { Sensitiv. } \\
\text { to } \\
\text { drying }\end{array}$ & $\begin{array}{c}\text { Density of } \\
\text { ceramic } \\
\text { shard, kg / } \\
\mathrm{m}^{3}\end{array}$ & $\begin{array}{c}\text { Flexural } \\
\text { strength, } \\
\mathrm{MPa}\end{array}$ & $\begin{array}{c}\text { Compre } \\
\text { ssion } \\
\text { strength, } \\
\mathrm{MPa}\end{array}$ \\
\hline 1 & $100: 0$ (contr) & - & 1,2 & 1787 & 4,6 & 7,2 \\
\hline 2 & $99: 1$ & - & 0,99 & 1833 & 6,0 & 13,0 \\
\hline 3 & $97: 3$ & - & 1,1 & 1810 & 5,3 & 10,0 \\
\hline 4 & $100: 0$ & 3 & 1,28 & 1882 & 5,0 & 8,0 \\
\hline 5 & $99: 1$ & 3 & 0,96 & 1920 & 6,5 & 15,0 \\
\hline 6 & $97: 3$ & 3 & 0,98 & 1912 & 5,5 & 12,0 \\
\hline
\end{tabular}

Analysis of the test results showed that the ceramic samples being subjected to processing showed a significant increase in physical and mechanical characteristics. The bending porosity increased by almost $2 \mathrm{MPa}$ in relation to the control one, the compressive strength was more than 2 times. The use of mechanoactivation reduces the sensitivity to drying of ceramic compositions. The sensitivity factor of the control sample was 1.28, which corresponds to the medium-sensitive clay. Samples with the addition of serpentinite, treated with cavitation, have a sensitivity to drying ratio of 0.98 , which corresponds to clays of low sensitivity. There is also a significant decrease in linear air shrinkage in samples with serpentinite (from 1 to $3 \%$ ): from $5.52 \%$ for control samples without additives up to $4.5 \%$ among those being treated in a hydrodynamic dispersant.

Obviously, additional mechanoactivation in the hydrodynamic dispersant results in a more uniform and dense structure of the ceramic shard and a uniform distribution of the additive throughout the volume (Figure 1).

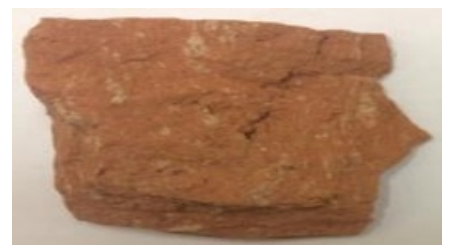

a)

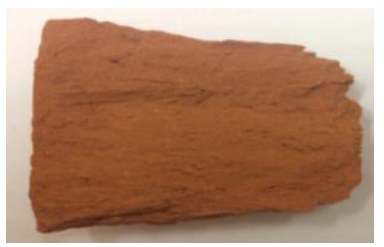

b)

Fig. 1. The image of the structure of the cleavage surface of a ceramic shard with the addition of serpentinite 3\%; a: without mechanoactivation, b: after mechanoactivation.

Investigations of the microstructure of the cleavage surface of ceramic shards, control one (a) and activated with the addition of serpentinite $3 \%$ (b), were carried out on an electronic microscope JEOLJSM-6000. The microstructure of the surfaces is shown in Figure 3. 


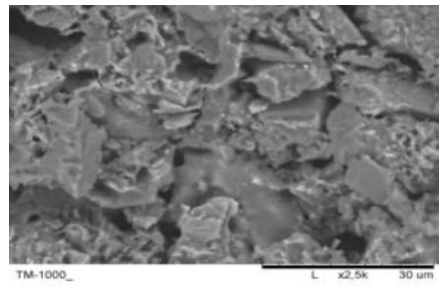

a)

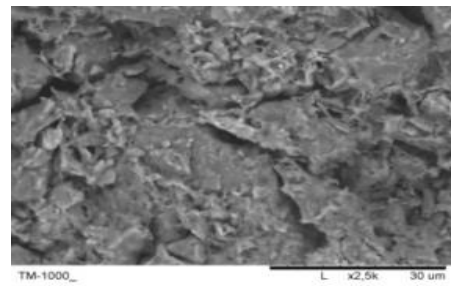

b)

Fig. 3. The microstructure of the surface of the samples of ceramic material, 2,500 times; a: the microstructure of the control sample's surface; b: microstructure of the activated sample's surface with the addition of serpentinite $3 \%$.

An analysis of the results of electron microscopy suggests that the microstructure of an activated ceramic shard, with the addition of serpentinite, contains more muallite-rich mixed crystals, as well as devitrified areas. Impregnations of magnesium oxide is not observed, it synergistically interacts in the system. MgO serves as a primer capable of making the melt more liquid, accelerating its devitrification.

Based on the studies carried out, the following conclusions can be drawn:

- Increasing the proportion of serpentinite in the ceramic composition to $3 \%$ allows to significantly improve the drying properties of products, reduce the primary deformations (air shrinkage) the development of which is the most dangerous phenomenon that violates the quality of the ceramic shard;

- Using serpentinite additives allows to increase the physical and mechanical characteristics of ceramic materials, as well as partially solve the problem of utilization of industrial waste;

- The effect of mechanoactivation on the ceramic composition manifests itself in a change in its granulometric composition, increasing in the micron and behind-micron fraction, an increase in plasticity, which is sintering in the solid phase during roasting affects. This contributes to improving the physical and mechanical properties of ceramic products and makes it possible to reduce the cost of electricity for their firing, due to a reduction in the sintering temperature of the ceramic mass;

- The ceramic mass activated in the cavitator, undergoing dispersion and homogenization, after firing has a more homogeneous and dense structure of the ceramic shard with a uniform distribution of the serpentinite additive throughout the volume, the proportion of unreacted magnesium is reduced, and the physico-mechanical characteristics;

- The activated ceramic mass, being more dispersed and homogeneous, makes it possible to exclude the operation of curing out from the technological process of brick production, leading to a reduction in energy inputs, emissions;

- Thus, mechanoactivation makes it possible to obtain a universal raw material for the production of ceramic bricks.

\section{References}

1. A. N. Bogdanov, L. A. Abdrakhmanova, Izvestiya KGASU, 3, 103-107 (2014).

2. A. N. Bogdanov, L. A. Abdrakhmanova, V. G. Khozin, High Technology and Innovation, 1, 46-49 (2014)

3. V. I. Bolyak, A. P. Zubyokhin, N D. Yatsenko, Building Materials, Equipment, Technologies of the XXI Century, 11, 18- 20 (2011)

4. M. V. Pleshko, V. D. Kotlyar, M. S. Pleshko, Refractories and Technical Ceramics, 3, 31-34 (2015)

5. M. V. Pleshko, M. S. Pleshko, Glass and Ceramics, 1, 21-24 (2015) 
6. A. M. Salakhov, K. A. Ariskina, R. A. Ariskina, Georesources, 18, 236-239 (2016)

7. V. A. Guryeva, V. V. Prokofieva, Building Materials, 8, 20-21 (2012)

8. D. V. Makarov, R. G. Melkonyan, O. V. Suvorova, V. A. Kumarova, Mining Information Analytical Bulletin, 5, 254-281 (2016)

9. A. A. Galenko, M. V. Pleshko, Construction Materials, 4, 60-65 (2014)

10. F. J. P. Sousa, A. P. Novaes, O. E. Alarcon, American Ceramic Society Bulletin, 85, 9101-9107 (2006)

11. A. V. Bogoviz, Y. V. Ragulina, N. V. Sitorkina, Advances in Intelligent Systems and Computing, 622, 597-602 (2018)

12. R. R. Menzes, M. I. Brasileiro, L. N. L. Santana, G. A. Neves, H. L. Lira, H. C. Ferreira, Waste Management and Research, 26, 362-368 (2008)

13. R. R. Menezes, L. N. L. Santana, G. A. Neves, H. C. Ferreira, Waste Management and Research, 11, 199-220 (2012)

14. R. D. Rawlings, J. P. Wu, A. R. Boccaccini, Journal of Materials Science, 41, 733-761 (2016)

15. G. A. Khater, Processing and Application of Ceramics, 6, 109-116 (2002)

16. S. K. Amin, H. A. Sibak, S. A. El-Sherbiny, M. F. Abadir, International Journal of Applied Engineering Research, 11, 2680-2685 (2016)

17. F. M. Flavitsky, Jour. Russian. Fiz. Chem., 34, 8-11 (1902)

18. V. B. Zaalishvili, T. T. Magkoev, Yu. K. Chernov, G. E. Tuayev, Geology and Geophysics of the South of Russia, 1, 17-23 (2017)

19. M. A. Promtov, Bulletin of the Tambov State Technical University, 23, 412-419 (2017)

20. D. S. Tsyplakov, A. V. Kornilov, T. Z. Lygina, E. N. Permyakov, Bulletin of the Kazan Technological University, 16, 86-90 (2011)

21. M. M. Dimitrijevic, M. Dojcinovic, A. Devecerski, R. Jancic-Heinemann, T. VolkovHusovic, Science of Sintering, 45, 97-105 (2013)

22. A. Shishkin, A. Korjakins, V. Mironovs, International Journal of Chemical, Nuclear, Materials and Metallurgical Engineering, 9, 734-737 (2015) 